\title{
Trends and rural-urban differences in asthma hospitalizations in Saskatchewan 1970-1989
}

\author{
A SENTHILSELVAN PhD \\ Department of Community Health and Epidemiology and Centre for Agricultural Medicine, \\ Department of Medicine, University of Saskatchewan, Saskatoon, Saskatchewan
}

A Senthilselvan. Trends and rural-urban differences in asthma hospitalizations in Saskatchewan 1970-1989. Can Respir J 1994;1(4):229-234.

OBJEctive: To examine the trends in hospitalization rates for asthma in Saskatchewan from 1970 to 1989 and to investigate the differences in asthma hospitalization rates between rural and urban dwellers.

DESIGN: Asthma hospitalization rates were calculated for the age groups 0 to 4,5 to 9,10 to 14,15 to 24,25 to 34,35 to 49 and 50 to 64 years for the period between 1970 and 1989. Only the first admission in each year for each person was included in the analysis. As the classification of asthma changed in 1978, trends in asthma hospitalization rates were investigated separately for the periods 1970 to 1978 and 1979 to 1989 , respectively. Rate ratios were obtained for male/female and rural/urban comparisons by fitting Poisson regression models.

SetTING: The hospitalization data for respiratory diseases for the province of Saskatchewan were examined by age group, sex and place of residence.

RESULT: No significant increases were observed in asthma hospitalization rates from 1970 to 1978 . In the period 1979 to 1989 , asthma hospitalization rates increased significantly among children under four years from $4.31 / 1000$ in 1979 to $7.04 / 1000$ in 1989. Among children under 14 years, asthma hospitalization rates were greater in boys than in girls. The converse was true for adults aged 15 and above, with women having a higher hospitalization rate for asthma than men. In adults aged 35 and above, rural dwellers had higher hospitalization rates for asthma than urban dwellers throughout the study period. In other age groups, although rural dwellers had higher asthma hospitalization rates than did urban dwellers during 1970 to 1984, the differences disappeared during 1985 to 1989.

CONCLUSION: Further studies are required to find reasons for the increase in asthma hospitalizations among young children under four years old and for the differences between rural and urban dwellers in the age group 35 years and above.

Key Words: Adults, Asthma, Children, Hospitalization, Morbidity, Rural populations

\section{Tendances et différences rurales et urbaines dans les hospitalisations liées à l'asthme en Saskatchewan de 1970 à 1989}

OB.ıEcif: Examiner les tendances dans les taux d'hospitalisations liées à l'asthme en Saskatchewan de 1970 à 1989 et analyser les différences dans les taux d'hospitalisations liées à l'asthme entre les habitants du milieu rural et ceux du milieu urbain.

MoDèLE: Les taux d'hospitalisations liées à l'asthme ont été calculés pour les groupes d'âge de 0 à 4,5 à 9,10 à 14,15 à 24,25 à 34,35 à 49 et 50 à 64 ans, de 1970 à 1989. On a seulement retenu la première hospitalisation de chaque année pour chaque personne dans l'analyse. Comme la classification de l'asthme a été mofifiée en 1978, les tendances dans les hospitalisations dues à l'asthme ont été analysées séparément pour les périodes allant respectivement de 1970 à 1978 et de 1979 à 1989. Les rapports des taux ont été obtenus pour une comparaison hommes/femmes et milieu rural/urbain en appliquant les modèles de régression de Poisson.

ConTEXTE : Les données relatives aux hospitalisations causées par des maladies respiratoires dans la province de la Saskatchewan ont été analysées par groupe d'âge, sexe et lieu de résidence.

RÉSultats : Aucune augmentation significative n'a été observée dans les taux d'hospitalisations de 1970 à 1978. Entre 1979 et 1989. les taux d'hospitalisations liées à l'asthme ont augmenté de manière significative parmi les enfants de moins de 4 ans en passant de 4,31/1 000 en 1979 à 7,04/I 000 en 1989. Parmi les enfants de moins de 14 ans, les taux d'hospitalisations étaient plus élevés chez les garçons que chez les filles. L'inverse était vrai pour les adultes de 15 ans et plus. les femmes démontrant un taux d'hospitalisation pour cause d'asthme plus élevé que les hommes. Chez les adultes de 35 ans et plus, ceux vivant en milieu rural démontraient un taux d'hospitalisation pour cause d'asthme plus élevé que ceux vivant en milieu urbain pendant toute la durée de l'étude. Dans les autres groupes d'âge, bien que les sujets résidant en milieu rural démontraient des taux d'hospitalisations pour cause d'asthme plus élevés que ceux résidant en milieu urbain de 1970 à 1984, ces différences avaient disparu de 1985 à 1989.

Conclusions : De nouvelles études s'imposent pour expliquer les raisons de l'augmentation des hospitalisations liées à l'asthme parmi les jeunes enfants de moins de 4 ans ainsi que les différences observées entre les patients vivant en milieu rural comparativement à ceux vivant en milieu urbain dans le groupe d’âge des 35 ans et plus. 
A SIIIMA MOREIDITY HAS BEEN REPOR TIST TO BE INCREAS ing in various countries including Canada and the United States $(1-8)$.

Wilkins and co-workers (1) investigated the changes in asthma morbidily and mortality from 1980 to 1988 in the 10 provinces of Canadit and reported that asthma montality in Salkkatchewan was among the highest in Canadil. Asthma morbidity in Saskatchewan decreased in children under 14 years and increased in adults aged 15 to 34 years (1). Although several studies have reported significant increases in hospitalization rates for asthma among children under four ycirs (3,5-9), no study has investigated the trends in atsthma hospitalizations for children in this age group in Saskatchewan. In this study, we examined the trends in atsthmat hospitalizations among children in the age groups 0 104,5109 and 10 to 14 years, and among adults 15 to 24,25 10 34,35 10 49 and 50 10 64 years, and investigated the differences in asthmat hospitatizations between urban and rural dwellers in Saskatchewan.

\section{METHODS}

Separation data: All residents of the province of Saskatchewan are enrolled in the Salskatchewan Health Services Plan (SHSP), which provides hospital care without costs for in-patient services. The discharge datat for all the respiratory diseases (Internattional Clatssilicution of Diseases, Ninth Revision, [ICD-9) 460 (0 519) were obtained from the Urban Hospitals Branch of the Satskitchewan Health Department for all 134 hospitals in the province. For each separation, age, sex, residence code, date of discharge, primary diagnosis of admission and length of hospital stay were provided to the investigator by the health department. Only the first admission of a patient in cach yeall was included in the analysis The population cligible for health coverage from the Saskatchewan government was also obtained for 1970 to 1989. The registered Native population and the mixed popu lation from northern Saskatchewan were excluded from this study.

Asthma hospitalization rates for children under four years were compared with those for atute and chronic/unspecified hronchitis (ICD 466, 490-491) and lower respiratory tract disease (pneumonia [ICD 480-486], emphysema [ICD 492] and pleurisy [ICD 5[1]). The atute and chronic/unspecified bronchitis category is hereafter referred to as "bronchitis" in this article.

ICD-8 coding scheme was used during the period 1970 (6) 1978 and it was replaced by ICD-9 coding scheme in 1979 Asthmatic bronchitis was coded under "bronchitis, unqualified' in ICD-8 and under 'asthma' in ICD-9. As the "bronchi tis, unqualified' category in the ICD-8 cording scheme included more than one disease group. it was not possible to reclassify asthmatic bronchitis ats asthma from the data obtained from the Saskatchewan Health Department.

Definition of rural/urban dwellers: Saskatchewan is divided into 298 administrative divisions termed Rural Municipalities (RMs). The municipalities are further divided intt cities and towns. The health department uses a five-digit code for each municipality, with the first three digits indicatting the

TABLE 1

Age specific asthma hospitalization rates (per 1000) for Saskatchewan population, 1970-1989

\begin{tabular}{|c|c|c|c|c|c|c|c|c|c|c|c|c|c|c|}
\hline \multirow[b]{3}{*}{ Year } & \multicolumn{14}{|c|}{ Age group (years) } \\
\hline & \multicolumn{2}{|c|}{$0-4$} & \multicolumn{2}{|c|}{$5-9$} & \multicolumn{2}{|c|}{$10-14$} & \multicolumn{2}{|c|}{$15-24$} & \multicolumn{2}{|c|}{$25-34$} & \multicolumn{2}{|c|}{$35-49$} & \multicolumn{2}{|c|}{$50-64$} \\
\hline & Number & Rate & Number & Rate & Number & Rate & Number & Rate & Number & Rate & Number & Rate & Number & Rate \\
\hline \multicolumn{15}{|c|}{ ICD-8 } \\
\hline 1970 & 278 & 3.57 & 204 & 2.08 & 129 & 1.29 & 120 & 0.75 & 67 & 0.70 & 185 & 1.25 & 291 & 2.22 \\
\hline 1971 & 316 & 4.24 & 218 & 2.34 & 144 & 1.46 & 101 & 0.63 & 61 & 0.65 & 165 & 1.14 & 315 & 2.38 \\
\hline 1972 & 359 & 4.96 & 253 & 2.89 & 175 & 1.80 & 117 & 0.72 & 62 & 0.65 & 150 & 1.06 & 331 & 2.49 \\
\hline 1975 & 293 & 4.34 & 247 & 3.42 & 186 & 2.02 & 126 & 0.74 & 63 & 0.60 & 137 & 1.02 & 295 & 2.18 \\
\hline 1976 & 249 & 3.57 & 207 & 2.89 & 149 & 1.67 & 145 & 0.81 & 53 & 0.47 & 100 & 0.74 & 250 & 1.84 \\
\hline 1977 & 235 & 3.30 & 225 & 3.15 & 142 & 1.66 & 153 & 0.84 & 58 & 0.48 & 106 & 0.79 & 239 & 1.75 \\
\hline 1978 & 293 & 4.09 & 259 & 3.63 & 162 & 2.00 & 163 & 0.88 & 80 & 0.63 & 108 & 0.80 & 279 & 2.04 \\
\hline \multicolumn{15}{|l|}{ ICD-9 } \\
\hline 1982 & 475 & 6.40 & 285 & 4.01 & 181 & 2.53 & 158 & 0.90 & 87 & 0.58 & 124 & 0.88 & 275 & 2.04 \\
\hline 1983 & 441 & 5.83 & 309 & 4.29 & 207 & 2.89 & 168 & 0.96 & 115 & 0.73 & 114 & 0.79 & 228 & 1.69 \\
\hline 1984 & 471 & 6.09 & 271 & 3.68 & 148 & 2.09 & 181 & 1.05 & 115 & 0.71 & 115 & 0.77 & 247 & 1.84 \\
\hline 1985 & 449 & 5.76 & 246 & 3.29 & 153 & 2.15 & 145 & 0.86 & 106 & 0.63 & 119 & 0.77 & 252 & 1.90 \\
\hline 1986 & 459 & 5.93 & 282 & 3.75 & 168 & 2.39 & 204 & 1.26 & 131 & 0.77 & 139 & 0.88 & 245 & 1.86 \\
\hline 1987 & 595 & 7.78 & 324 & 4.29 & 224 & 3.16 & 189 & 1.21 & 135 & 0.79 & 161 & 0.98 & 215 & 1.66 \\
\hline 1988 & 520 & 7.06 & 266 & 3.51 & 182 & 2.56 & 193 & 1.29 & 143 & 0.84 & 143 & 0.85 & 273 & 2.12 \\
\hline 1989 & 504 & 7.04 & 254 & 3.39 & 177 & 2.49 & 198 & 1.40 & 128 & 0.77 & 140 & 0.81 & 210 & 1.66 \\
\hline
\end{tabular}




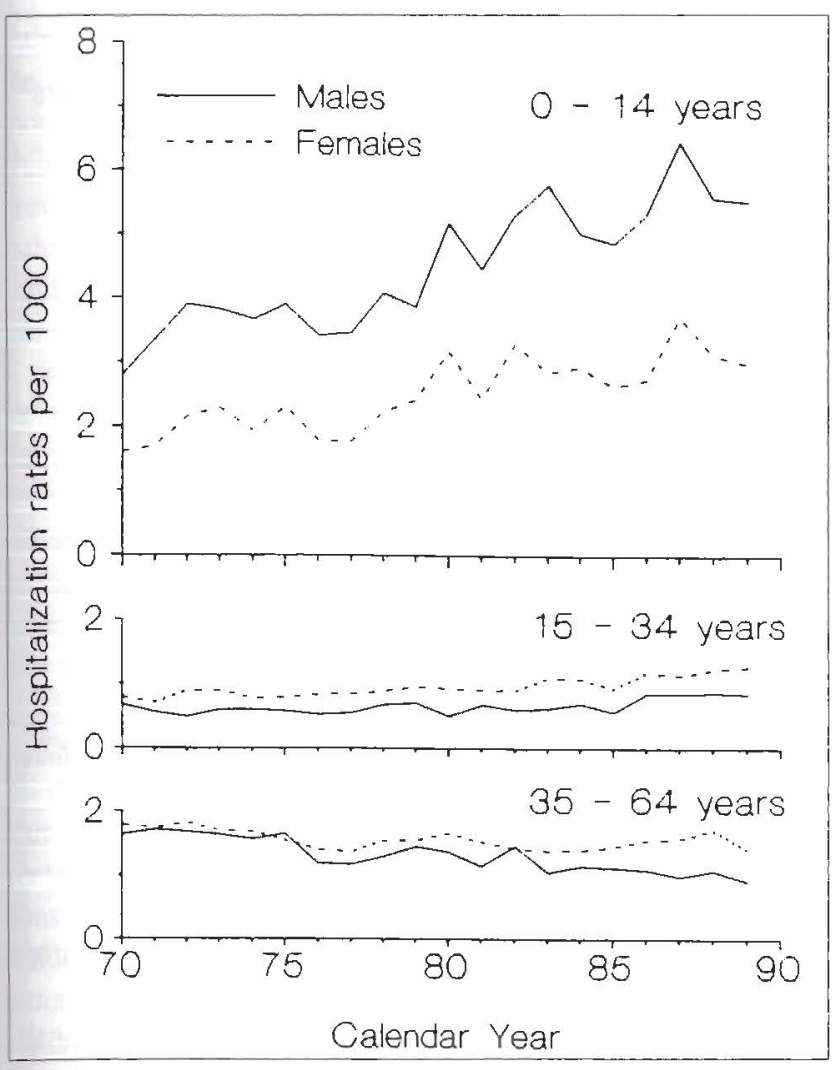

Figure 1) Age-and sex-specilic hosphati-ation rates for asthme in Saskatchewan. 1970-89

municipality and the last two digits indicating town or city. Any municipality with a population of 10,000 or more was defined as an urban municipality. There were I0 urban municipalities by this definition: Estevan, Lloydminster, Moose Jaw, North Battleford, Prince Albert, Regini, Saskatoon, Swift Current. Weyburn and Yorkton. The rest of the smaller municipalities were considered as nural. The population of larger municipalities included in the rural cattegory ranged from 4771 to 6040): Melfort (6040)). Humboldt (5177), Melville (4983). Kindersley (4826) and Nipawin (477I). Because the population of the largest municipality included in the rural category was well below $10,(0) 00$, a population of 10,000 seemed to be a reasonable cut-off point for division into rural and urbain areas. The subjects residing in urban and rural municipalities were defined as 'urban dweilers' and rural dwellers", respectively.

During the study period. there were six base hospitals, seven regional hospitals, seven large community hospitals and 114 community hospitals in Saskatchewan. All 134 hospitals provide acute care services. The populations in the 10 "urban municipalities" are served by six base hospitals, seven regional hospitals and three large community hospitals while the populations in 'rural municipalities' are served by four large community hospitals and I 4 community hospitals. Statistical methods: Age and sex specific asthma hospitaliration rates were obtained by dividing the number of hospitalizations for asthma (ICD 493) by the appropriate covered populations for the ycars 1970) to 1989. Trends in asthma

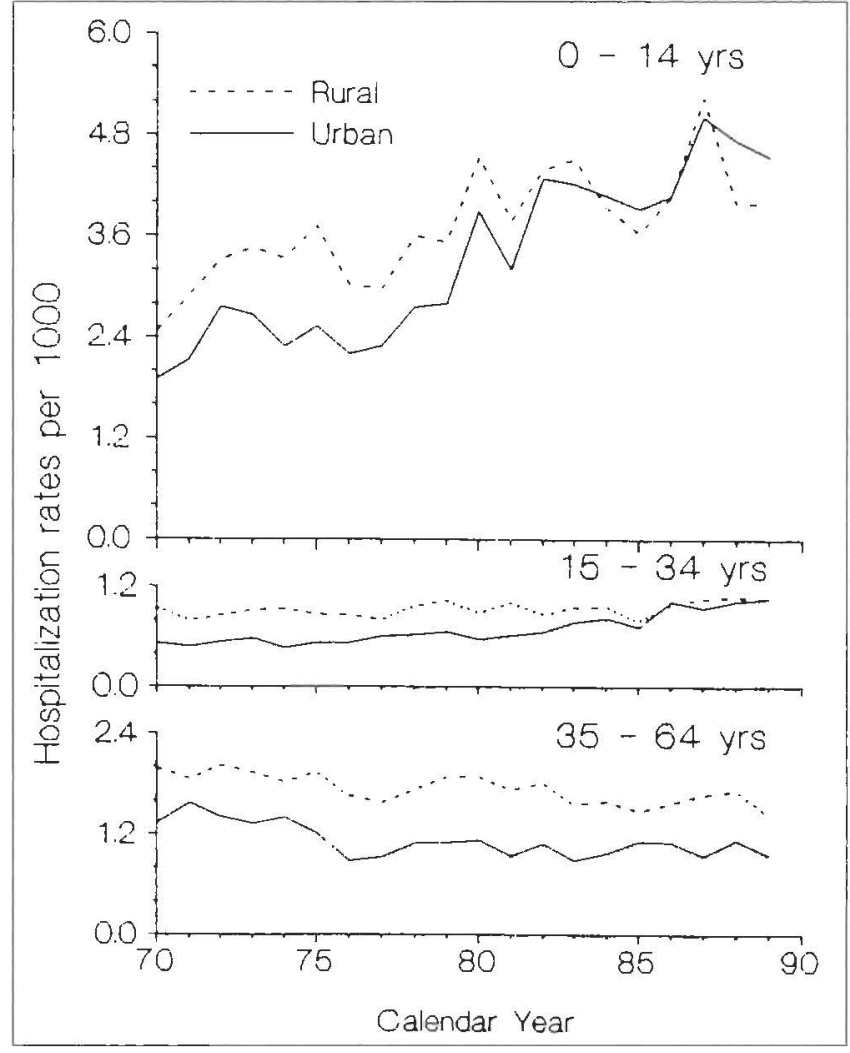

Figure 2) Age-spectife hosyitalization rates for astlmat for reral and urban dwellers in Sorkathewan. 1970).89

hospitalizations were investigated separately for the two periods 1970) 10, 1978 and 1979) to 1989 during which ICD-8 and ICD-y coding schemes were used. The number of hospitalizat inns in age, sex and time specific category was assumed to have a Poisson distribution with a mean $\mathrm{Nr}$, where $\mathrm{N}$ is the population at risk in that category and $r$ is the rate of hospi. talization during that period (10). Significance of the trends was tested by fitting an ordinal (independent) variable in the Poisson regression model and then examining the significance of the slope (11). For comparison between rural and urban dwellers, Poisson regression models were fitted for seven age groups 0 to 4,5 to 9 , 10 to 14,15 to 24,25 to 34 , 35 to 49 and 50 to 64 years, respectively. for four time periods 1970 to 1974, 1975 to 1979, 1980 to 1985 and 1986 to 1989. The dependent variable in the Poisson regression models wals the hospitalization rate and the independent variables were $\mathrm{scx}$ and an indicator variable to identify the rural/urban populations. The Poisson regression models were fitted using the statistical package generalized linear interaction nodel (GLIM release 3, Numerical Algerithms Group, Oxford. UK), with hospitalization rate as the Y-variate, log as the link function and covered population as an offset. The error terms were assumed to have a Poisson distribution (10).

\section{RESULTS}

The frequencies and rates of hospitalizations for asthmil are given in Table 1 for the age groups 0 to 4,5 to 9,10 to 14 , 15 to 24,25 to 34,35 to 49 and 50 to 64 years, respectively. 


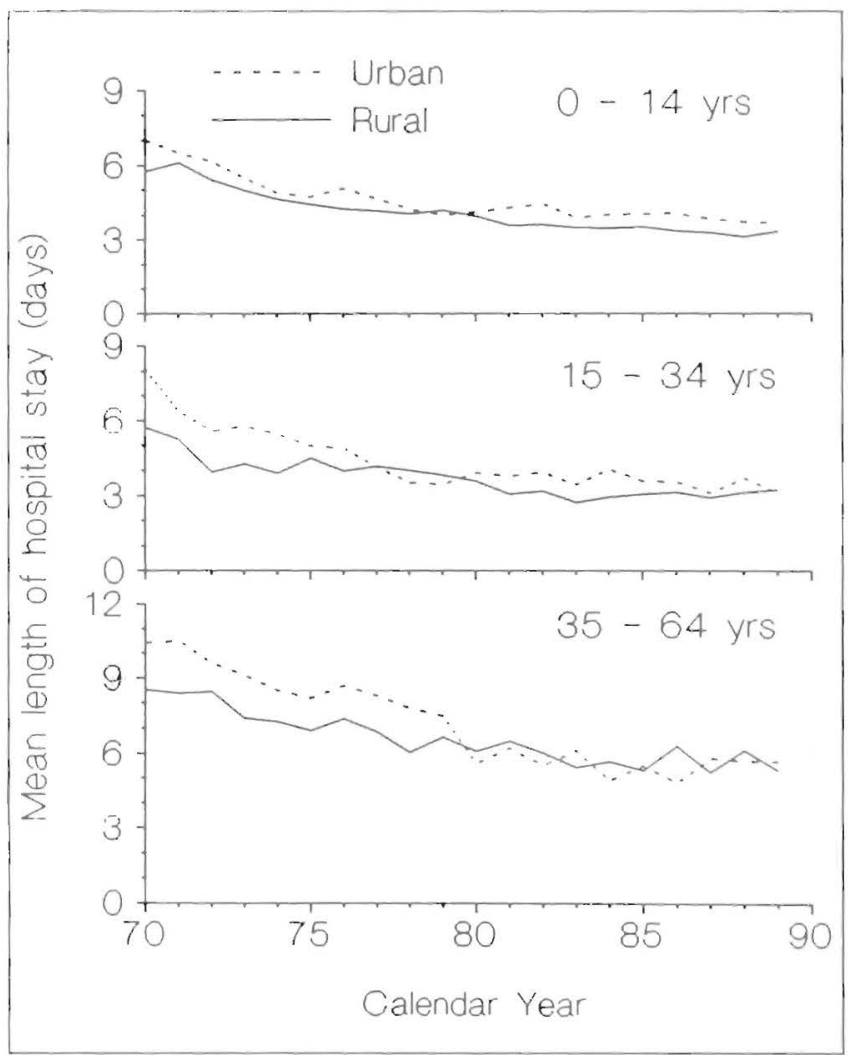

Figure 3) Mean length of hospital stay for rural and urban dwellers in Saskatchewan. 1970-89

No significant trends were observed during the period 1970 to 1978. In the period 1979 to 1989 , a significant trend was observed only in children aged 0 to 4 years. In this age group, asthma hospitalization rates increased significantly from $4.31 / 1000$ in 1979 to $7.04 / 1000$ in $1989(\mathrm{P}<0.001)$.

The asthma hospitalization rates are shown in Figure 1 for male and female populations. In children aged 0 to 14 years, hospitalization rates were almost double among boys compared with girls. The rate ratio (RR) of hospitalization for asthma for boys compared with girls was 1.8 (95\% confidence interval $[\mathrm{CI}] 1.72$ to 1.94 ) during the period 1985 to 1989. This pattern was reversed in the age groups 15 to 34 and 35 to 64 years, with women having higher hospitalization rates for asthma than men. In the period 1985 to 1989, RRs of hospitalization for asthma for women compared with men were 1.4 (CI 1.31 to 1.59 ) in the age group 15 to 34 years and 1.5 (CI 1.36 to 1.64 ) in the age group 35 to 64 years, respectively.

As shown in Figure 2, asthma hospitalization rates were greater among rural than among urban populations in children aged 0 to 14 years and young adults aged 15 to 34 years until 1984, but the differences disappeared from 1985 onwards. In adults over 35 years, the hospitalization rates for asthma were greater among rural than among urban dwellers throughout the study period. In this age group, RRs for rural dwellers in comparison with urban dwellers were 1.5 (CI 1.31 to 1.65 ) for women and 1.6 (CI 1.38 to 1.84 ) for men during the period 1985 to 1989. As shown in Figure 3, means

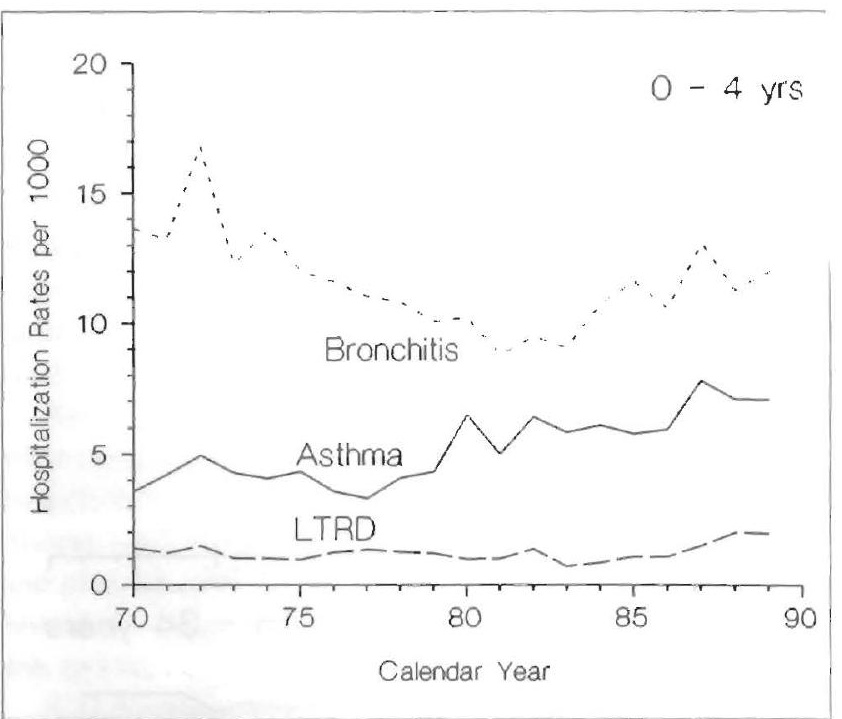

Figure 4) Hospitalization rates for asthma, bronchitis and lower tract respiratory diseases (LTRD) for children aged 0 to four vear: in Saskatchewan, 1970-89

of length of hospital stay were very similar in rural and urban dwellers in all age groups.

To investigate whether the increases in asthma hospitalization rates in children aged 0 to four years were due to labelling other diseases as asthma, asthma rates in this age group were compared with those for bronchitis and lower tract respiratory diseases (Figure 4). If the increases in asthma hospitalization rates were due to labelling other diseases as asthma, the hospitalizations for bronchitis and lower tract respiratory diseases would be expected to decline throughout the study period. However, the hospitalization rates for bronchitis and lower tract respiratory diseases decreased only until 1983 and increased thereafter.

\section{DISCUSSION}

In this study, only children under four years of age had a significant increase in asthma hospitalizations during the period 1979 to 1989. No increases were observed in asthma hospitalizations during 1970 to 1978 in any age group. Several other studies have also reported significant increases in asthma hospitalizations among children under four years during the 1980s (3,5-9). There may be several reasons for the increase in asthma hospitalization rates in this age group. Increases in hospitalizations for bronchitis and lower tract respiratory diseases during the latter part of the study indicates that the increases in asthma hospitalization rates may not be due to labelling other diseases as asthma. An increase in the prevalence of asthma or an increase in the proportion of children with severe asthma seeking hospital admission would result in increased hospitalization rates for asthma.

In the present study, only the first admission of each patient in each year was included and readmissions within each year were excluded. This was done so that the hospitalization rates for asthma would not be inflated by repeated admissions to the hospital by a few subjects with severe 
asthmatic attacks. Anderson and co-workers (3) reported that the increase in the frequency of asthma hospitalization was more likely to be due to an increase in the proportion of children with severe asthma attacks than to an increase in the prevalence of asthma. When readmissions were included, the asthma hospitalization rates increased, but the results were similar to those obtained with including only the first admissions.

Indoor air pollution may play an important role in the increases in the asthma morbidity among young children in Saskatchewan. Because of the long winter conditions in Saskatchewan, houses built in the past decade are 'energy efficient' so that outside air does not get in easily. This restricts air circulation and increases the build-up of cigarette smoke and allergens inside the houses. Maternal smoking has also been shown to be a risk factor for wheezing in young children $(12,13)$.

The number of working mothers has increased recently in developed countries. As a result, more young children under four years attend dilycarc and preschool where they come in contact with children with viral infections. The viral infections are well known triggers of asthma attacks $(14,15)$. The children who attend daycare are at a higher risk of developing asthma. Thus, increases in asthma morbidity among young children niay be related to changes in lifestyles of the parents in the past decade.

A negative correlation wats recently reported between patrental knowledge of asthma and hospitalization of the child (16). Parental knowledge of asthma is required for compliance with medication, for management of severe asthma attacks and for the child to adopt a normal life. With recent changes in asthma diagnosis, medication and management, parental knowledge of asthma is essential for prevention and control of severe asthma attacks in the child. Thus, lack of parental knowledge about new medications and changes in the management of asthma may increase the need for repeated hospitalizations of the child.

Our results are consistent with the previous findings that the hospitalization rates for asthma are greater for boys than girls among children under 14 years of age, and greater for women than for men among adults aged 15 and above $(1,17,18)$.

In adults aged 35 ind above, rural dwellers had higher hospitalization rates lor asthma than did urban dwellers

ACKNOWLEDGEMENTS: This research was supported by an establishment grant from the College of Medicine, University of Saskatchewan. The author, not the Urban Hospitals Branch of the Saskatchewan Health Department, is responsible for the study and its conclusions.

\section{REFERENCES}

1. Wilkins K, Mao Y. Trends in rates of admission to hospital and death from asthma among children and young adults in Canatit during the 1980s. Can Med Assoc J 1993;148:185-90.

2. Mitchell EA. International trends in hospital admission rates for asthma. Arch Dis Child 1985;60:295-300.

3. Anderson HR. Increase in hospitalization for childhood asthmit: throughout the study period. This was true for both men and women. However, among children and young adults, the differences in asthma hospitalizations between rural and urban dwellers were apparent during 1970 to 1984 but disappeared during the period 1985 to 1989. Mitchell (18) investigated differences between rural and urban dwellers in New Zealand and reported that asthma admission rates were greater in rural than in urban dwellers among adults aged 45 and above, and that it was reversed in young adults aged 25 and below, with urban dwellers having greater admission rates for asthma than rural dwellers.

There may be several reasons for the higher hospitalization rates for asthma that we have observed among rural dwellers aged 35 and above in Saskatchewan. In this age group, the main occupation of the rural population in Saskatchewan is grain farming. A recent study investigated risk factors for asthma in a rural population in Saskatchewan and found that grain farming was significantly related to self-reported asthma (19). In another study, use of carbamate insecticides was shown to be associated with self-reported asthma among grain farmers in Saskatchewan (20). These results raise the possibility that grain farming may be related to increased hospitalizations for asthma among rural dwellers aged 35 years and above.

Another possible reason for greater hospitalization rates for asthma among the rural dwellers may be that there are more hospital beds available in rural hospitals than in urball hospitals. Thus, patients with milder asthma may be admitted to the hospital more often in rural than in urban areas. Also, asthmatics among rural dwellers may get admitted to the hospital more often than those among the urban dwellers because the asthmatics in rural areas live a greater distance from the hospital and the asthmatics in urban areas may be managed at home knowing that they are within easy access of it hospital.

\section{CONCLUSION}

Asthma hospitalization rates appear to be greater in children under four years than in older children and are greater among rural dwellers than urban dwellers in the age group 35 and above. Further studies are required to determine reasons for the increase in asthma hospitalizations and for the differences in admission patterns between rural and urban dwellers.

trends in referral, severity, and readmissions from 1970 to 1985 in a health region of the United Kingdom. Thor: 1989:44:614-9.

t. Mitchell EA, Jackson RT. Recent trends in asthma mortality, morbidity and management in New Zealand. J Asthma 1989:26:349-54.

5. Gergen PJ, Weiss KB. Changing patterns of asthma hospitalization among children 1979 to 1987. JAMA 1990;264: 168-92.

6. Mortality and morbidity from respiratory diseases in childhood in the Netherlands, 1980- 1987. Eur Respir J 1991;4:429-34.

7. Carman PG, Landau LI. Increased pediatric admissions with asthma in Western Australia - a problem of diagnosis? Med .I Aust 1990;152:23-6. 
8. Carr W, Zeitel L, Weiss K. Vartations in asthmal hospitalizations and deaths in New York City. An J Public Health 1992;82:59-65.

9. Vollner WM, Buist AS, Osbornc ML. Twenty year trends in hospital discharges for asthma among members of a health maintenance organization. J Clin Epidemiol 1992:45:(9)(9)- I(6)6

10. Breslow NL: Daly NF: Statistical methods in cancer research. Vol It. The desing and analysis of cohort studies (IARC Scientific Publicalion No 82). L yon: International Agency for Reseatrch on ('ancer. 1087

1 1. Kaldor J, Khlat M, Parkin DM. Shiboski S, Steiniz R. Log-linear models for cancer risk among migrants. Int . Epidemiol 1990; 19:233-9.

12. Pedreira I A, Guandolo VL. Feroli Fs. Mcllal GW. Weiss IP. Involuntary smoking and incidence of respiratory illness during the lirst yeat of life. Pediatrics 1985:75:594-7.

1.3. Gortmaker SL. Walker DK, Jacobs IHH, Ruch-Ross H. Parental smoking and the risk of childhood asthna. An J Public Health $1982 ; 72: 574-9$.
14. Pattemore PK, Johnston SL, Bardin P(i. Viruses as precipitants of asthma symptoms. I. Epidemiology. (Clin Exp Allergy 1992:22:325-36.

15. Bardin PG, Johnston SL, Pattemore PK. Viruses as precipitants of asthma symptoms. II. Physiology and mechanisms. Clin Exp Allergy 1992;22:809-22.

16. Brook U, Mendelberg A, Heim M. Increasing parental knowledge of asthma decreases the hospitalization of the child. J Asthma 1993;30:45-9.

17. Skobeloff EM, Spivey WH, St Clair SS, Schoffstall JM. The influence of age and sex on asthma admissions. JAMA 1992;268:3437-40.

18. Mitchell EA. Demographic characteristics of asthma admissions to hospitals. NZ Med J 1986;99:576-9

19. Senthilselvan A, Chen Y, Dosman JA. Predictors of asthma and wheezing among adults: grain farming, sex, and smoking. Am Rev Respir Dis 1993;148:667-70).

20. Senthilselvan A, McDuffie HH, Domman JA. Association of asthma with use of pesticides: results of a cross-sectional survey of farmers. Am Rev Respir Dis 1992; 146:884-7. 


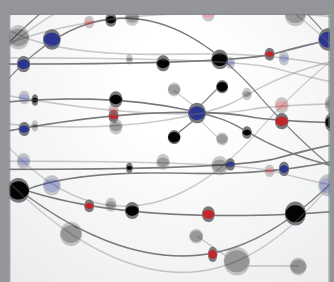

The Scientific World Journal
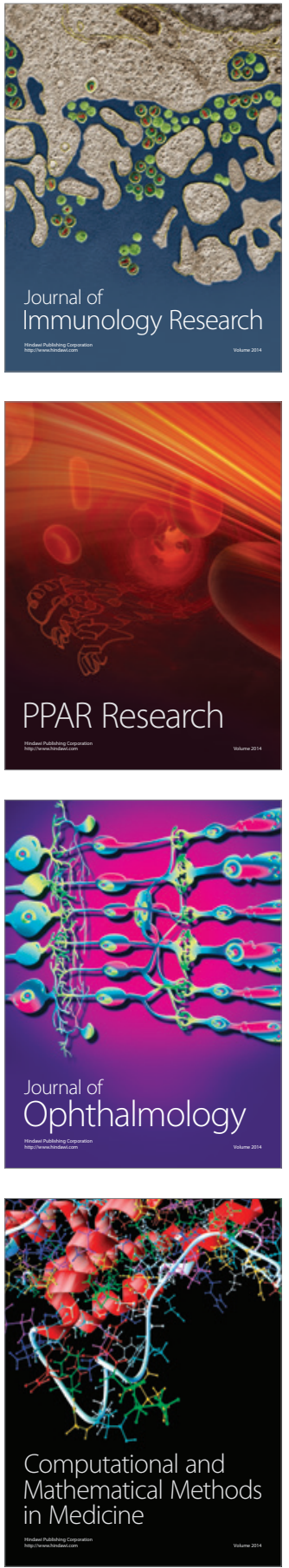

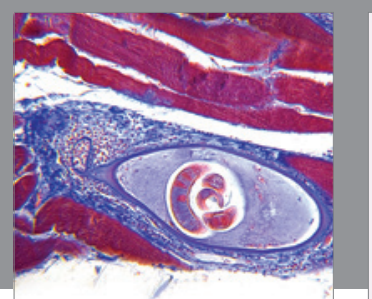

Gastroenterology Research and Practice

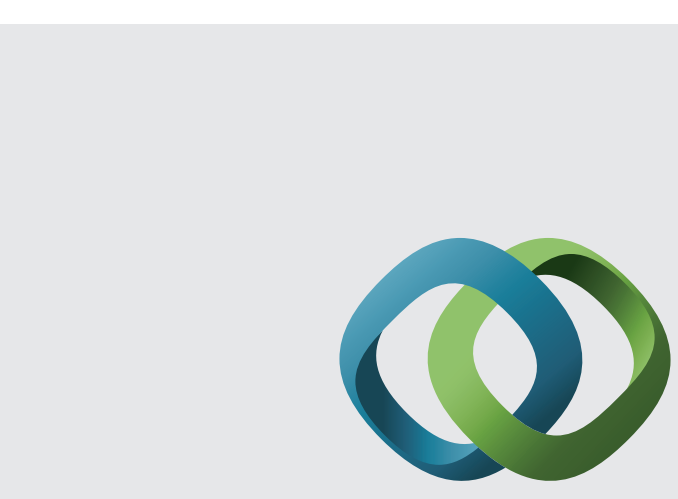

\section{Hindawi}

Submit your manuscripts at

http://www.hindawi.com
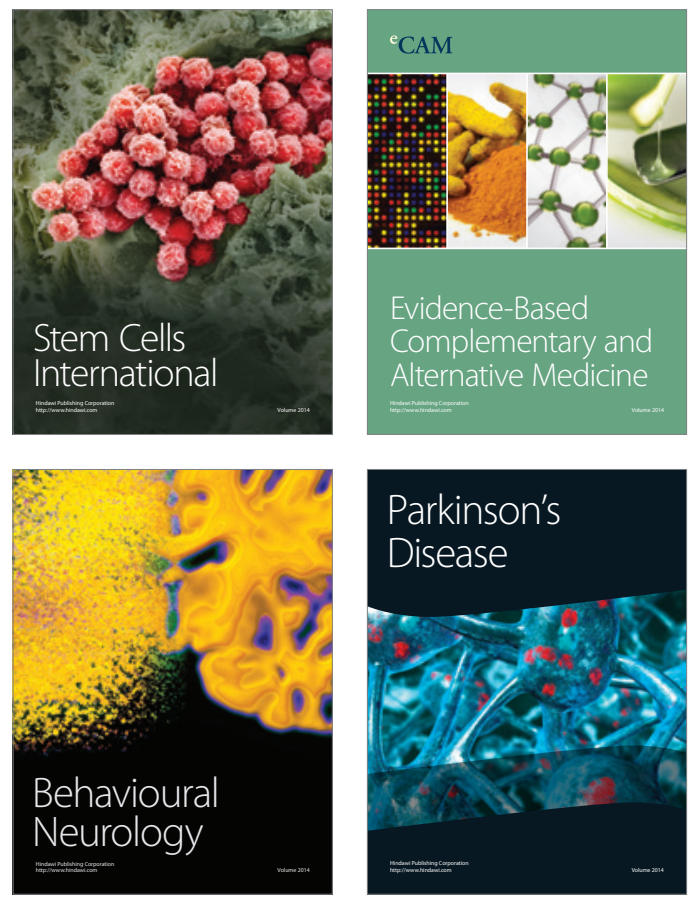
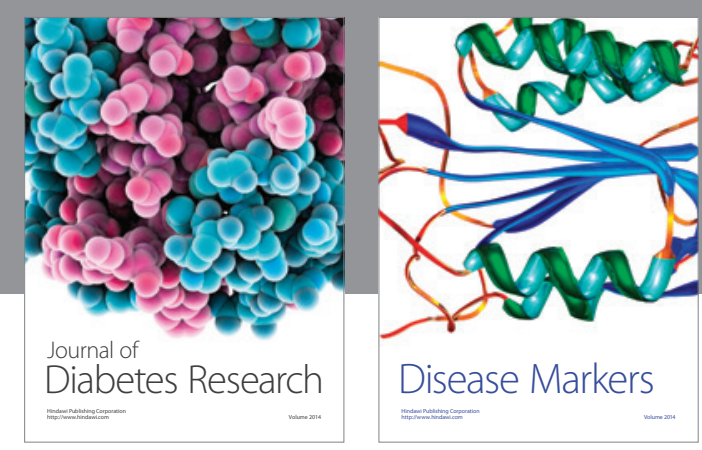

Disease Markers
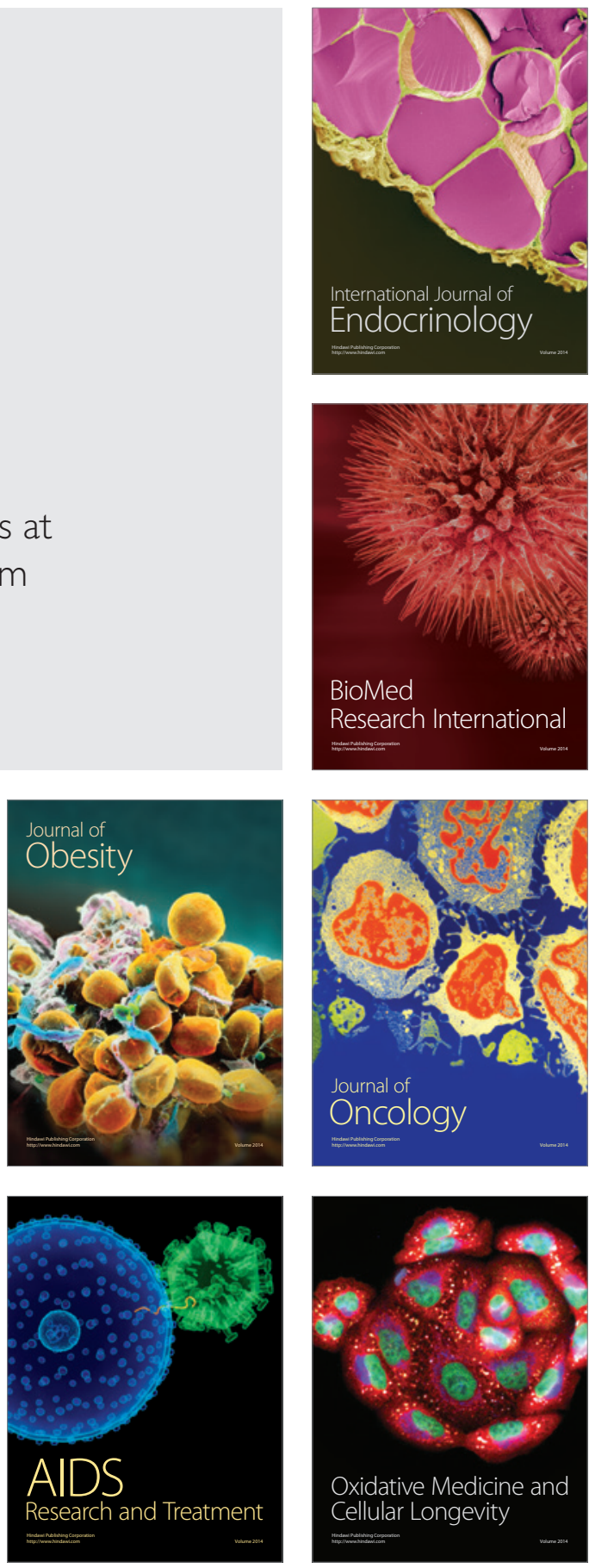